University of Wollongong

Research Online

Australian Institute for Innovative Materials -

Papers

Australian Institute for Innovative Materials

$1-1-2013$

Covalently linked biocompatible graphene/polycaprolactone composites for tissue engineering

\author{
Sepidar Sayyar \\ University of Wollongong, sepidar@uow.edu.au \\ Eoin Murray \\ University of Wollongong, eoin@uow.edu.au \\ Brianna C. Thompson \\ University of Wollongong, brianna@uow.edu.au \\ Sanjeev Gambhir \\ University of Wollongong, sanjeev@uow.edu.au \\ David L. Officer \\ University of Wollongong, davido@uow.edu.au
}

See next page for additional authors

Follow this and additional works at: https://ro.uow.edu.au/aiimpapers

Part of the Engineering Commons, and the Physical Sciences and Mathematics Commons

Research Online is the open access institutional repository for the University of Wollongong. For further information contact the UOW Library: research-pubs@uow.edu.au 


\title{
Covalently linked biocompatible graphene/polycaprolactone composites for tissue engineering
}

\begin{abstract}
Two synthesis routes to graphene/polycaprolactone composites are introduced and the properties of the resulting composites compared. In the first method, mixtures are produced using solution processing of polycaprolactone and well dispersed, chemically reduced graphene oxide and in the second, an esterification reaction covalently links polycaprolactone chains to free carboxyl groups on the graphene sheets. This is achieved through the use of a stable anhydrous dimethylformamide dispersion of graphene that has been highly chemically reduced resulting in mostly peripheral ester linkages. The resulting covalently linked composites exhibit far better homogeneity and as a result, both Young's modulus and tensile strength more than double and electrical conductivities increase by 14 orders of magnitude over the pristine polymer at less than 10 per cent graphene content. In vitro cytotoxicity testing of the materials showed good biocompatibility resulting in promising materials for use as conducting substrates for the electrically stimulated growth of cells.
\end{abstract}

\section{Keywords}

engineering, linked, tissue, covalently, composites, polycaprolactone, graphene, biocompatible

Disciplines

Engineering | Physical Sciences and Mathematics

\section{Publication Details}

Sayyar, S., Murray, E., Thompson, B. C., Gambhir, S., Officer, D. L. \& Wallace, G. G. (2013). Covalently linked biocompatible graphene/polycaprolactone composites for tissue engineering. Carbon, 52 (February), 296-304.

\section{Authors}

Sepidar Sayyar, Eoin Murray, Brianna C. Thompson, Sanjeev Gambhir, David L. Officer, and Gordon G. Wallace 


\section{Covalently linked biocompatible graphene/polycaprolactone composites for tissue engineering}

By Sepidar Sayyar, Eoin Murray*, Brianna C. Thompson, Sanjeev Gambhir, David L. Officer and Gordon G. Wallace*

ARC Centre of Excellence for Electromaterials Science (ACES), Intelligent Polymer Research Institute, AIIM Facility, Innovation Campus, University of Wollongong, NSW 2522, Australia.

Two synthesis routes to graphene/polycaprolactone composites are introduced and the properties of the resulting composites compared. In the first method, mixtures are produced using solution processing of polycaprolactone and well dispersed, chemically reduced graphene oxide and in the second, an esterification reaction covalently links polycaprolactone chains to free carboxyl groups on the graphene sheets. This is achieved through the use of a stable anhydrous dimethylformamide dispersion of graphene that has been highly chemically reduced resulting in mostly peripheral ester linkages. The resulting covalently linked composites exhibit far better homogeneity and as a result, both Young's modulus and tensile strength more than double and electrical conductivities increase by $\approx 14$ orders of magnitude over the pristine polymer at less than $10 \%$ graphene content. In vitro cytotoxicity testing of the materials showed good biocompatibility resulting in promising materials for use as conducting substrates for the electrically stimulated growth of cells. 


\section{Introduction}

Polymer nanocomposites with nanosized carbonaceous fillers have shown large improvements in mechanical, conductivity and barrier properties over the pristine polymers. For example, the storage modulus and conductivity of polyimide are greatly improved by integrating carbon nanotubes into the polymer $[1,2]$ and the addition of a small amount of fullerene materials has led to a $30-40 \%$ increase in Young's modulus and the tensile strength of polyamides. [2]

Graphene is a single layer two-dimensional graphitic carbon material packed densely in a honeycomb crystal structure, with promising mechanical, electrical, optical, thermal and magnetic properties. It has also been shown to be biocompatible and even beneficial in the growth of cells.[3-5] It is reported that graphene-based polymer nanocomposites show much improved mechanical and electrical properties when compared to other carbon filler based nanocomposites.[6-9] These unique properties have attracted researchers to investigate graphene as a reinforcing agent in biocompatible composite materials in order to improve mechanical, thermal and electrical properties.[10-14]

Poly(E-caprolactone) $(\mathrm{PCl})$ is a biodegradable and biocompatible aliphatic polyester with good resistance to water, solvents and oil, synthesized by the ring opening polymerization of $\varepsilon$-caprolactone. Polycaprolactone’s unique mechanical and chemical properties have resulted in its extensive commercial development for biomedical and materials applications.[15-17] The addition of an electrically conducting filler, such as graphene, opens up a number of further possible applications, such as conducting substrates for the electrically stimulated growth of cells.

Recently, a number of authors [19, 20] have shown that the addition of non-conducting graphene oxide as a filler in polycaprolactone results in improvements in the mechanical 
properties of PCl. Composites of PCl and graphene oxide (GO) have also been synthesised by ring opening polymerization of $\varepsilon$-caprolactone using GO as an initiator [19] and have shown that GO has an excellent nucleating effect on the crystallization of PCl. To the best of our knowledge there have been no previous reports on the use of conducting reduced graphene nanosheets in polycaprolactone composites.

In this work, we use highly reduced graphene dispersions to prepare graphene/polycaprolactone composites. Highly reduced chemically converted graphene

exhibits far greater conductivity than graphene oxide resulting in highly conducting composites. Composites are prepared using two different methods; a mixing method producing binary mixtures of graphene in a polymer matrix and a chemical method resulting in polymer that is covalently linked to the remaining functionalities on the periphery of the graphene sheet. The resulting graphene/biopolymer materials retained the biocompatibility and processability of the polymer but with conductivities and mechanical properties enhanced by orders of magnitude due to the graphene filler.

\section{Experimental}

\subsection{Materials}

ع-caprolactone (97 \%), N,N-dimethylformamide, N,N'-dicyclohexylcarbodiimide (DCC), 4dimethylaminopyridine (DMAP), Dulbecco’s modified Eagle's medium (DMEM), methanol, dichloromethane, tin (II) ethylhexanoate (95 \%), polycaprolactone (MW 80,000) and triethylamine were sourced from Sigma-Aldrich and used as received. Graphite powder was obtained from Bay Carbon. Milli-Q water with a resistivity of $18.2 \mathrm{~m} \Omega \mathrm{cm}^{-1}$ was used in all preparations.

\subsection{Preparation of graphene oxide (GO)}


Graphene oxide was synthesized from natural graphite powder using a modified Hummers’ method in two steps using $\mathrm{K}_{2} \mathrm{~S}_{2} \mathrm{O}_{8}, \mathrm{P}_{2} \mathrm{O}_{5}$ and $\mathrm{H}_{2} \mathrm{SO}_{4}$ followed by $\mathrm{H}_{2} \mathrm{SO}_{4}, \mathrm{KMnO}_{4}$ and $\mathrm{H}_{2} \mathrm{O}_{2}$ to achieve better oxidation of graphite $(20,21)$.

\subsection{Preparation of chemically converted graphene (CCG) dispersions}

Graphene oxide (62.5 g) was diluted with deionised water (2 L) and sonicated for 80 min. Then, hydrazine $(400 \mu \mathrm{L})$ and ammonia $(4 \mathrm{~mL})$ were added and the solution heated at $90{ }^{\circ} \mathrm{C}$ for $1 \mathrm{hr}$. A further aliquot of hydrazine (3 mL) was added to the solution and the mixture was heated and kept at $90{ }^{\mathrm{O}} \mathrm{C}$ for two hours under constant stirring. After cooling to the room temperature, the solution was acidified with $\mathrm{H}_{2} \mathrm{SO}_{4}$ (aq. 30\%), then the agglomerated graphene powder was filtered and washed until the waste water was at a neutral $\mathrm{pH}$. The agglomerated graphene powder was filtered and dried in vacuum oven at $50{ }^{\circ} \mathrm{C}$ for 2 days.

To form a stable suspension, dried CCG (300 mg) was added to dimethylformamide (DMF) (150 ml, moisture content $\leq 350 \mathrm{ppm}$ by Karl-Fischer). Triethylamine (50 $\mu \mathrm{l})$ was added and the solution was extensively sonicated with continuous cooling under a dry nitrogen purge. DMF (300 ml) and triethylamine $(500 \mu \mathrm{l})$ were then added and the suspension was further sonicated under nitrogen. The dispersion was centrifuged to separate any agglomerated graphene sheets and the resulting supernatant $\left(0.5 \mathrm{mg} \mathrm{ml}^{-1}\right)$ was stable for several months without any agglomeration.

\subsection{Preparation of polycaprolactone $(\mathrm{PCl})$}

In a standard synthesis for a chain length of $\approx 40,000$, caprolactone $(5 \mathrm{ml})$ was mixed with tin 2-ethylhexanoate $(50 \mu \mathrm{l})$ in a flask that was evacuated then purged with nitrogen. The mixture was reacted using microwave irradiation $(100 \mathrm{~W}$ max $)$ at a constant temperature of $140{ }^{\circ} \mathrm{C}$ for 1 hour. The crude solid product was dissolved in dichloromethane and precipitated in cold methanol, filtered and dried in a vacuum oven at $50{ }^{\circ} \mathrm{C}$. The chain length could be easily controlled by varying the reaction time. 


\subsection{Preparation of PCl-CCG composites}

Graphene/polycaprolactone binary mixtures (mixPCl-CCG) were prepared by mixing polycaprolactone in an appropriate amount of a $0.5 \mathrm{mg} \mathrm{ml}^{-1}$ stable solution of DMF-dispersed graphene at $75{ }^{\circ} \mathrm{C}$ for 3 hours before cooling to room temperature. The polymer blends were then precipitated in cold methanol, filtered and dried in a vacuum oven at $50{ }^{\circ} \mathrm{C}$.

Covalently linked graphene/PCl composites (cPCl-CCG) were prepared by mixing polycaprolactone in an appropriate amount of a $0.5 \mathrm{mg} \mathrm{ml}^{-1}$ stable solution of DMF-dispersed graphene at $75^{\circ} \mathrm{C}$ for 1 hour. 50mg of DMAP was added followed by the slow addition of DCC and stirred at $75{ }^{\circ} \mathrm{C}$ for a further 4 hours before cooling to room temperature. The polymer composites were then precipitated in cold methanol, filtered and dried in a vacuum oven at $50{ }^{\circ} \mathrm{C}$.

\subsection{Characterisation}

Microwave-assisted polymerization was carried out in a CEM Discover 2.45-GHz microwave oven. Raman spectra were recorded on a Jobin Yvon Horiba HR800 Raman microscope using a $632 \mathrm{~nm}$ laser line and a 300-line grating. Scanning electron microscopy (SEM) images were collected with a field-emission SEM instrument (JEOL JSM-7500FA). Samples were sputter-coated (EDWARDS Auto 306$)$ with a thin layer of platinum $(\approx 3 \mathrm{~nm}$ thickness). X-ray powder diffraction (XRD) analysis was performed using GBC MMA diffraction

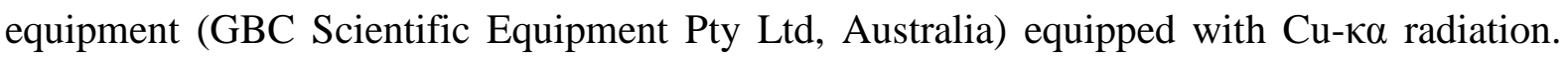
Thermal gravimetric analysis (TGA) was performed in using TGA Q500, TA Instruments with a heating rate of $10{ }^{\circ} \mathrm{C}$ under nitrogen atmosphere. Differential scanning calorimetric (DSC) analysis was performed on a DSC Q100, TA Instruments. 5 to $8 \mathrm{mg}$ of the sample was presealed into an aluminum pan and first heated to above the melting temperature (Tm) of the polymer $\left(100{ }^{\circ} \mathrm{C}\right)$, then cooled to $0{ }^{\circ} \mathrm{C}$ at $10^{\circ} \mathrm{C} \mathrm{min}{ }^{-1}$, the temperature increased to above 100 ${ }^{\circ} \mathrm{C}$ at $10{ }^{\circ} \mathrm{C} \mathrm{min}^{-1}$. All sonication was done using a Brandson Digital Sonicator (S450D, 500 
W, $40 \%$ amplitude). Mechanical properties were tested using an Instron 5566 Universal Testing Machine (USA). To prepare samples for mechanical properties tests, the samples were hot pressed at $100{ }^{\circ} \mathrm{C}$ to obtain a $0.1 \mathrm{~mm}$ thick film. The film then was cut to strips with a width of $3 \mathrm{~mm}$ and a length of $20 \mathrm{~mm}$. The tensile properties of the samples were measured with a constant rate of $10 \mathrm{~mm} \mathrm{~min}^{-1}$.

\subsection{Cell culture}

Materials were prepared for cell culture by attachment of chamber slides directly onto the surface using silicon glue, and sterilisation by soaking the surfaces with $70 \%$ ethanol before air drying in a biological safety cabinet. The sterilised materials were soaked in DMEM with penicillin/streptomycin for 24 hours before the cells were plated. For live/dead cell imaging, L-929 cells (a mouse fibroblast cell line) were seeded in DMEM supplemented with 10\% foetal bovine serum (FBS) at 5000 cells $\mathrm{cm}^{-2}$ of PCl-CCG composite, and incubated at $37^{\circ} \mathrm{C}$ in $5 \% \mathrm{CO}_{2}$ for 48 hours. After 48 hours, the cells were removed from the incubator and stained with calcein AM and propidium iodide for 10 minutes before imaging with a Zeiss AxioImager microscope. Image analysis for cell counting was performed using Image Pro Plus, and cell numbers were averaged over at least $3.6 \mathrm{~mm}^{2}$ of the culture surface, with microscope images taken from random, separate areas of the culture well. For growth curves of cells on the materials, three cell lines were used. L-929 cells (in DMEM + 10\% FBS), PC12 cells (rat phaemocryocytoma cells, in DMEM $+5 \%$ FBS plus 10\% horse serum) and C2C12 (mouse myoblast, in DMEM + 10\% FBS) cells were seeded onto the materials at 25000 cells/mL (approx 8000 cells/cm²), and incubated for up to 4 days on the materials. At 2, 24, 48, 72 and 96 hours, cells were harvested by removal of media and lysis of the cells in $50 \mu \mathrm{L} 0.1 \%$ sodium dodecyl sulfate/TE (tris ethylenediaminetetraacetic acid) buffer. A Pico Green assay was performed on $10 \mu \mathrm{L}$ of the lysed cell solutions diluted in $90 \mu \mathrm{L}$ TE buffer to quantify the amount of DNA in the solutions by addition of $100 \mu \mathrm{L}$ of Pico Green reagent 
(diluted 1:200 in TE buffer), subsequent incubation for 5 min and reading of the fluorescence of each well using a $485 \mathrm{~nm}$ excitation and $520 \mathrm{~nm}$ emission on a FLUOstar Omega (BMG Labtech) microplate reader.

\section{Results and Discussion}

The introduction of highly reduced graphene into many polymers is challenging given that stable graphene dispersions are typically prepared in water, precluding the effective introduction of exfoliated graphene nanoplatelets into water-insoluble polymers. Removal of the water leads to graphene aggregates, which are difficult to redisperse in either organic solutions of the polymer or the pristine polymer itself. This has prompted us to prepare an anhydrous dispersion of chemically converted graphene (CCG) in dimethylformamide (DMF) that is more highly reduced than our previously prepared aqueous CCG dispersion [29] and stable for more than a year at a concentration of $0.5 \mathrm{mg} \mathrm{ml}^{-1}$. The full details of this DMF CCG dispersion will be published elsewhere (ref: S. Gambhir, E. Murray, D.L Officer, manuscript in preparation). The stable DMF dispersion of CCG then allowed us to readily prepare a range of covalently linked and solution mixed polycaprolactone-graphene composites (0.1-10 wt.\% graphene)

The covalently linked graphene/polycaprolactone composites visually showed excellent dispersion of graphene in the polymer matrix even on hot-pressing and could be easily resuspended in a suitable solvent. On the other hand, composites produced using solution mixing showed washing-out of polymer during the precipitation and washing step, resulting in poor control of graphene content (initial addition of 5 wt.\% graphene resulted in a composite graphene content of almost $17 \%$ ). They also exhibited visible agglomerates in a hot-pressed thin film and in solution.

\subsection{Thermal Analysis}


Thermal gravimetric analysis (TGA) shows that the addition of graphene, whether in a binary mixture or a covalently linked composite, has very little effect on the decomposition temperature of polycaprolactone. The pure polymer $(\mathrm{MW} \approx 80,000)$ shows a monotonic weight loss at approximately $380{ }^{\circ} \mathrm{C}$ assigned to the decomposition of the polymer chains (Fig. 1). The graphene/polycaprolactone composites show a similar weight-loss profile and, as CCG weight losses are minimal in this temperature range, the residual weight after full decomposition of the polymer can be assigned to the graphene content. The graphene percentage calculated from TGA analysis of the composites prepared by covalent attachment method (cPCl-CCG) is very consistent with the percentage of graphene added to the reaction initially and indicates good attachment of the polymer. However, the graphene percentage in the mixtures (mixPCl-CCG) is very different to that added to the reaction mixture. This is consistent with the observation of polymer being washed out of the composite during precipitation.

(a)

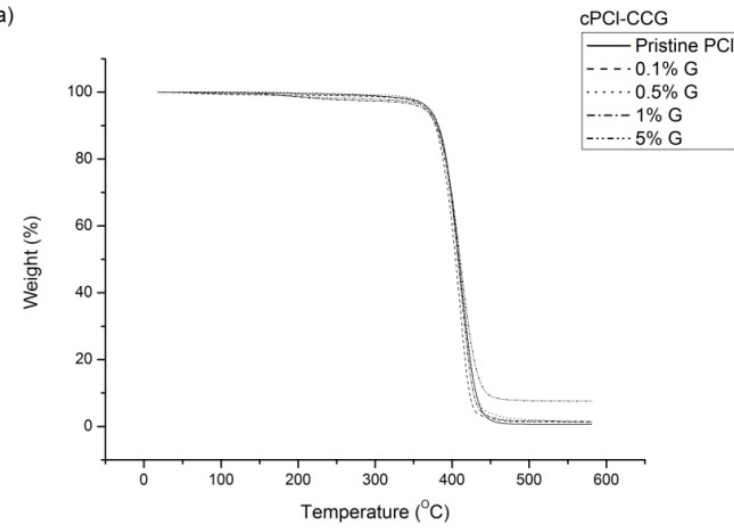

(b)

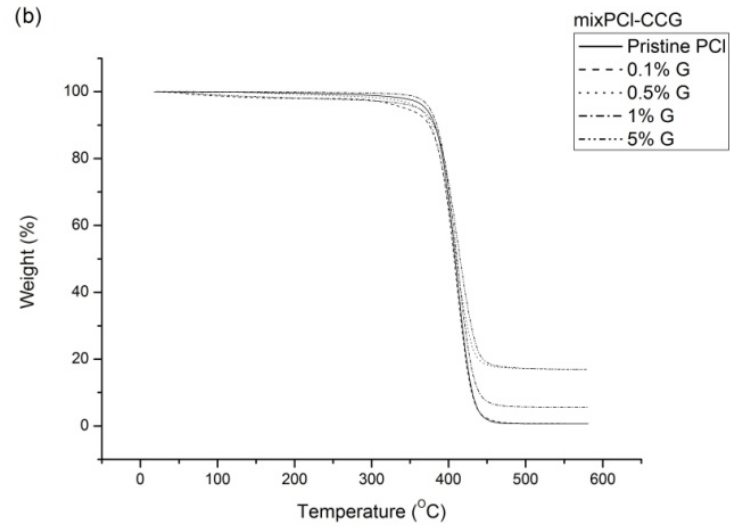

Figure 1. Thermal gravimetry curves of PCl-CCG composites. The residual weight after full decomposition of the polymer indicates the amount of graphene in composites

Differential scanning calorimetry (DSC) showed that the addition of graphene to polycaprolactone either covalently or as a mixture did not significantly affect the melting point of the $\mathrm{PCl}$ composites, which remains at $55-60{ }^{\circ} \mathrm{C}$ (Fig. 2). However, the addition of graphene increases the crystallization temperature for all of the composites. Addition of just 
$0.1 \%$ graphene results in very large increases in the crystallization point temperature from 19 ${ }^{\circ} \mathrm{C}$ in pristine $\mathrm{PCl}$ to $33{ }^{\circ} \mathrm{C}$ in the composite. This is likely to be due to the nucleating effect of graphene on PCl crystallization. Increasing addition of graphene further increases the crystallization temperature and broadens the crystalization peak, indicating confined mobility of polymer chains in the composite.

The nucleating effect of graphene nanosheets on the crystallisation of $\mathrm{PCl}$ is also confirmed by polarised optical microscopy (figure 3) on cooling materials below the crystallisation temperature which shows that spherulites of pure PCl are much larger in size and less densely packed than the graphene doped material.
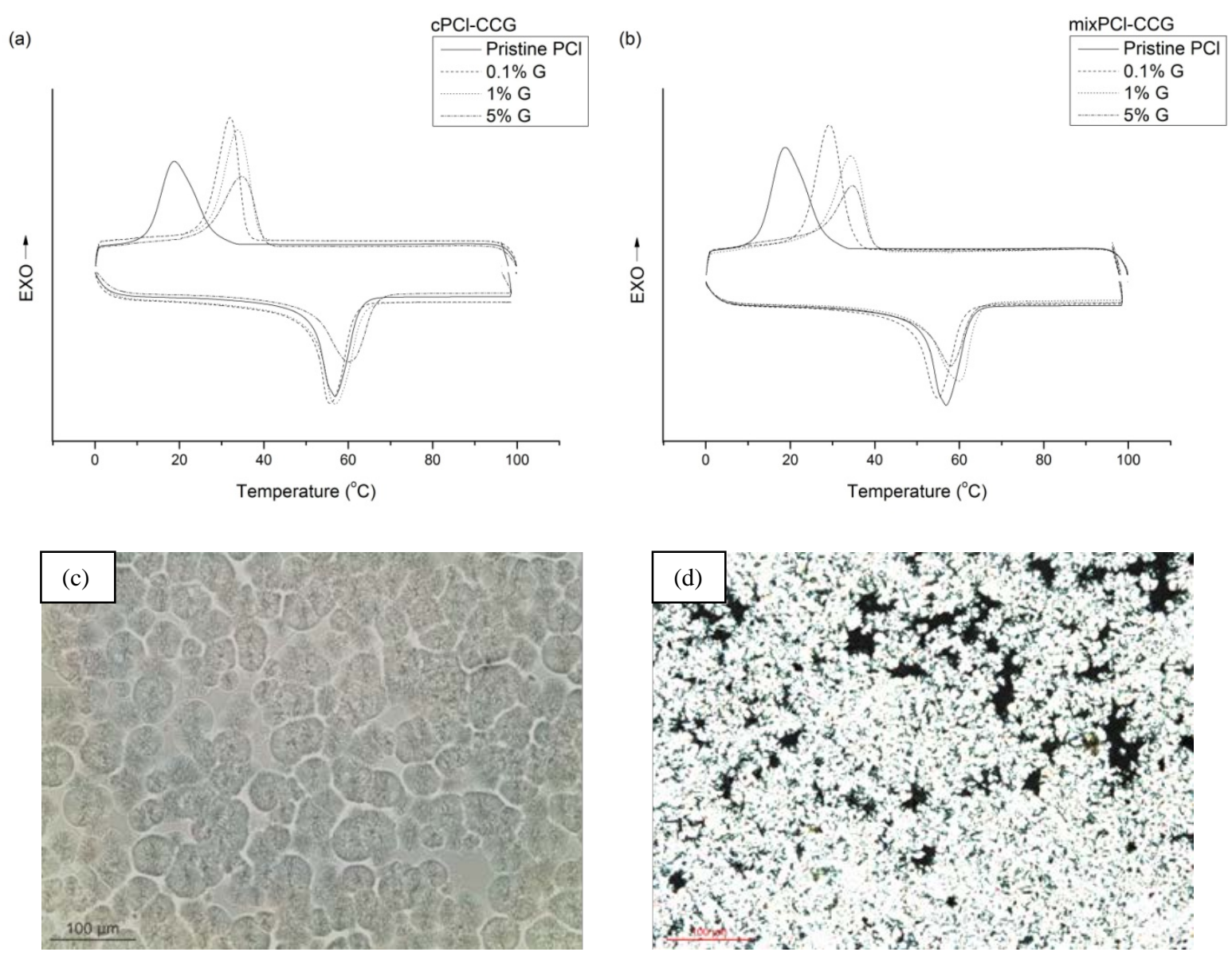

Figure 2. Differential scanning calorimetry curves of (a) cPCl-CCG and (b) mixPCl-CCG composites. The addition of graphene generally has little effect on the melt temperature but increases the crystallization temperature of the composites. Polarised optical microscopy images taken below the crystallisation temperature of pure PCl (c) and cPCl-CCG (d) showing the difference in spherulite size and density. 


\subsection{Material Composition and Morphology}

In the scanning electron microscopy images of the graphene/PCl composites in figure 3, the two samples have clearly different fracture surfaces, which reflect underlying differences in morphology agglomeration, alignment and bonding of the graphene nanosheets to the matrix.[6,7] The graphene filler appears dispersed more homogenously inside the polymer matrix in the $\mathrm{cPCl}-\mathrm{CCG}$ composite. This ordering is due to the covalently linked polymer on the graphene sheet forcing the retention of sheet separation even on precipitation. In the mixed composite (mixPCl-CCG), the polymer can be washed out from between sheets resulting in the observed agglomeration and poor alignment of graphene sheets inside the polymer matrix.
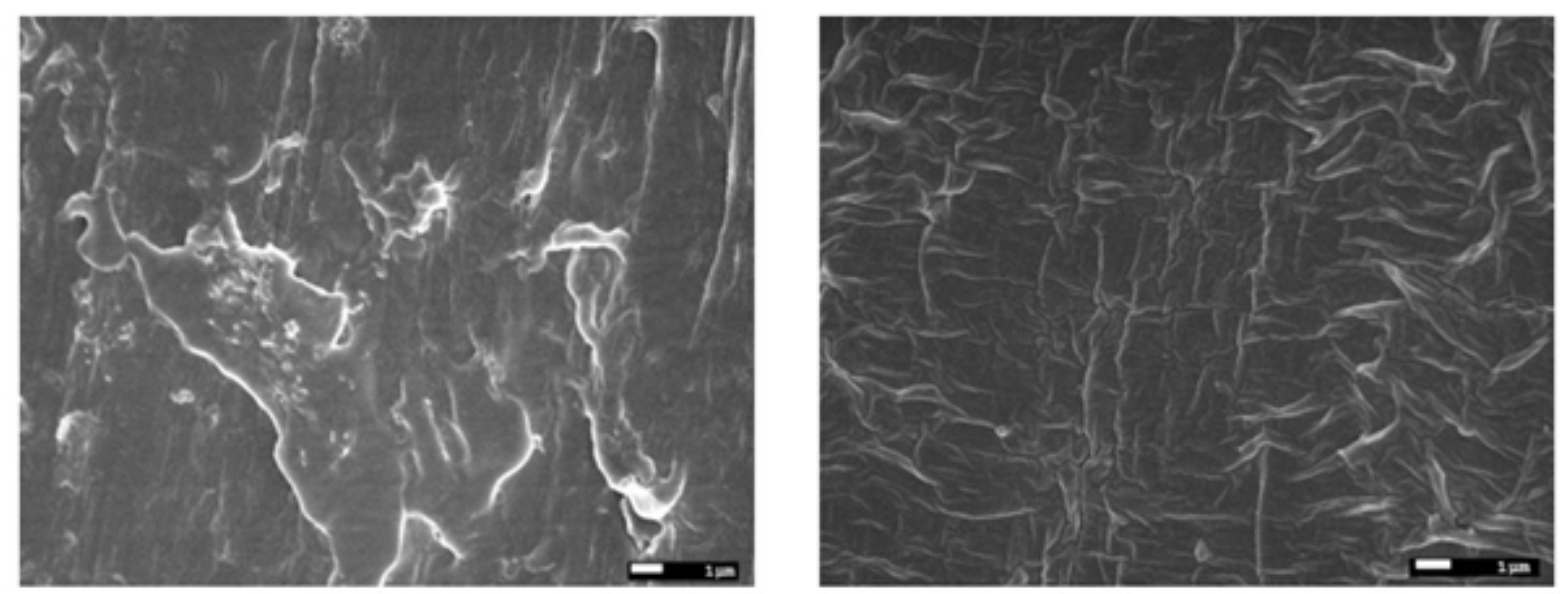

Figure 3. Cross-sectional scanning electron microscopy images of (a) mixPCl-CCG and (b) cPCl-CCG composites

Figure 4 shows the $\mathrm{X}$-ray diffraction patterns of polycaprolactone and graphene/PCl composites with varying graphene contents. The polymer diffraction pattern is typical of PCl with two major peaks at 21.3 and at $23.72 \theta$ [20, 21] Addition of graphene did not significantly affect the XRD patterns, except for a slight decrease in the peak at $2 \theta=21.3^{\circ}$ indicating a slight decrease in the crystallinity of the graphene/PCl composites similar to the effect observed by DSC. As such, it can be assumed that the chemical structure of the polymer is not significantly altered with increasing graphene content. 


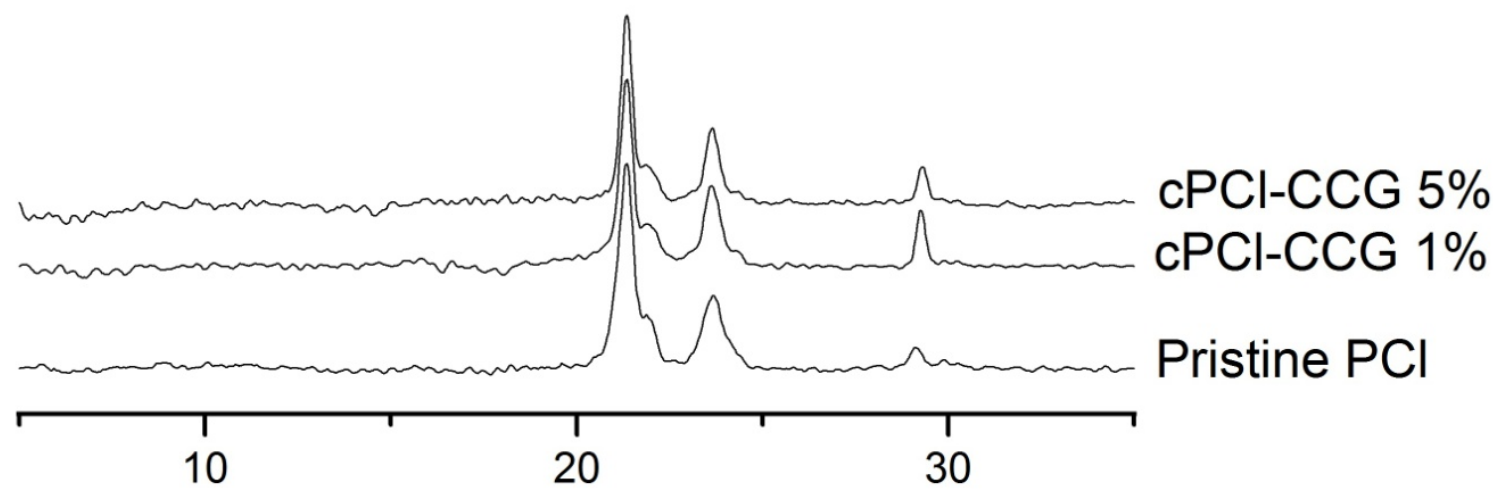

2 Theta (Degree)

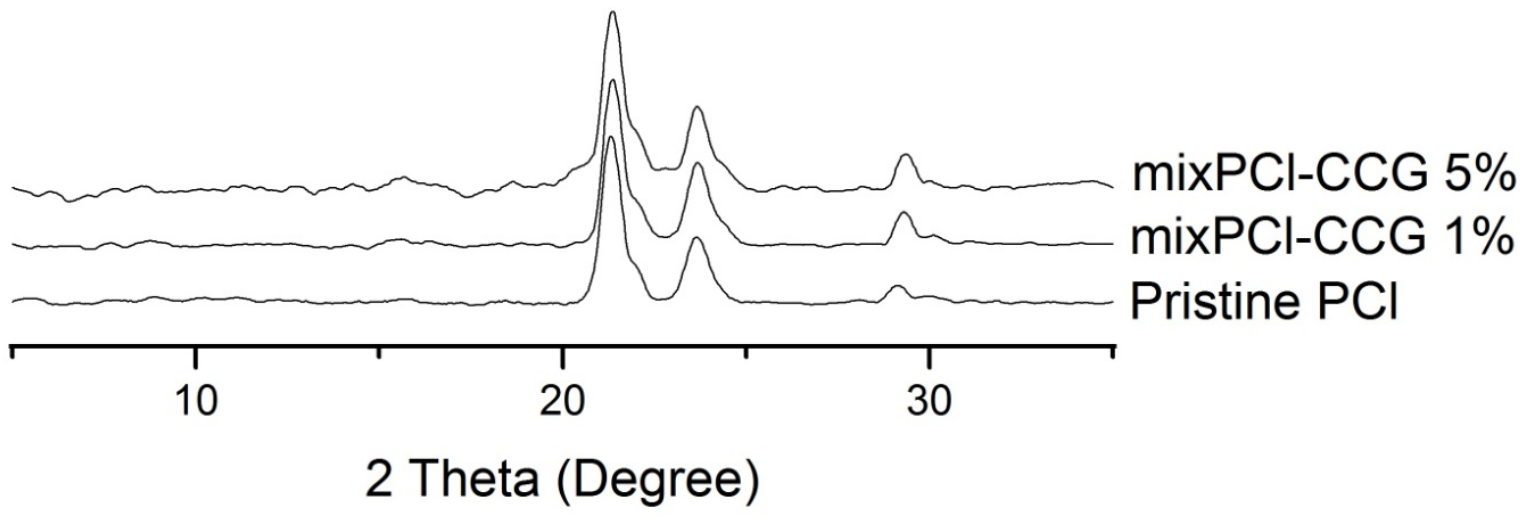

Figure 4. X-ray diffraction patterns of mixPCl-CCG and cPCl-CCG composites. The peaks can be attributed to the polymer component of the composite.

The Raman spectrum of PCl shows the characteristic peaks at $1726 \mathrm{~cm}^{-1}(v \mathrm{C}=\mathrm{O}), 1060 \mathrm{~cm}^{-1}$ and $1106 \mathrm{~cm}^{-1}$ (skeletal vibration) and $1281-1305 \mathrm{~cm}^{-1}$ attributable to $\mathrm{CH}_{2}$ groups.[27, 28] Figure 5 shows the effect of increasing graphene content on the Raman spectra of graphene/PCl composites synthesized by covalent attachment and mixing methods. On increasing addition of CCG, the peaks due to $\mathrm{PCl}$ are less visible as the intensity of the characteristic D and G bands of graphene are greater than that of PCl. In samples with highest graphene contents, only the $\mathrm{D}$ and $\mathrm{G}$ band graphene peaks are visible. The ratio of the intensities of the graphene $\mathrm{D}$ and $\mathrm{G}$ bands $\left(\mathrm{I}_{\mathrm{D}} / \mathrm{I}_{\mathrm{G}}\right)$ decreases slightly with increasing graphene 
content. This can be attributed to a decrease in the crystalline size of the composite on increasing the graphene content.[30, 31]
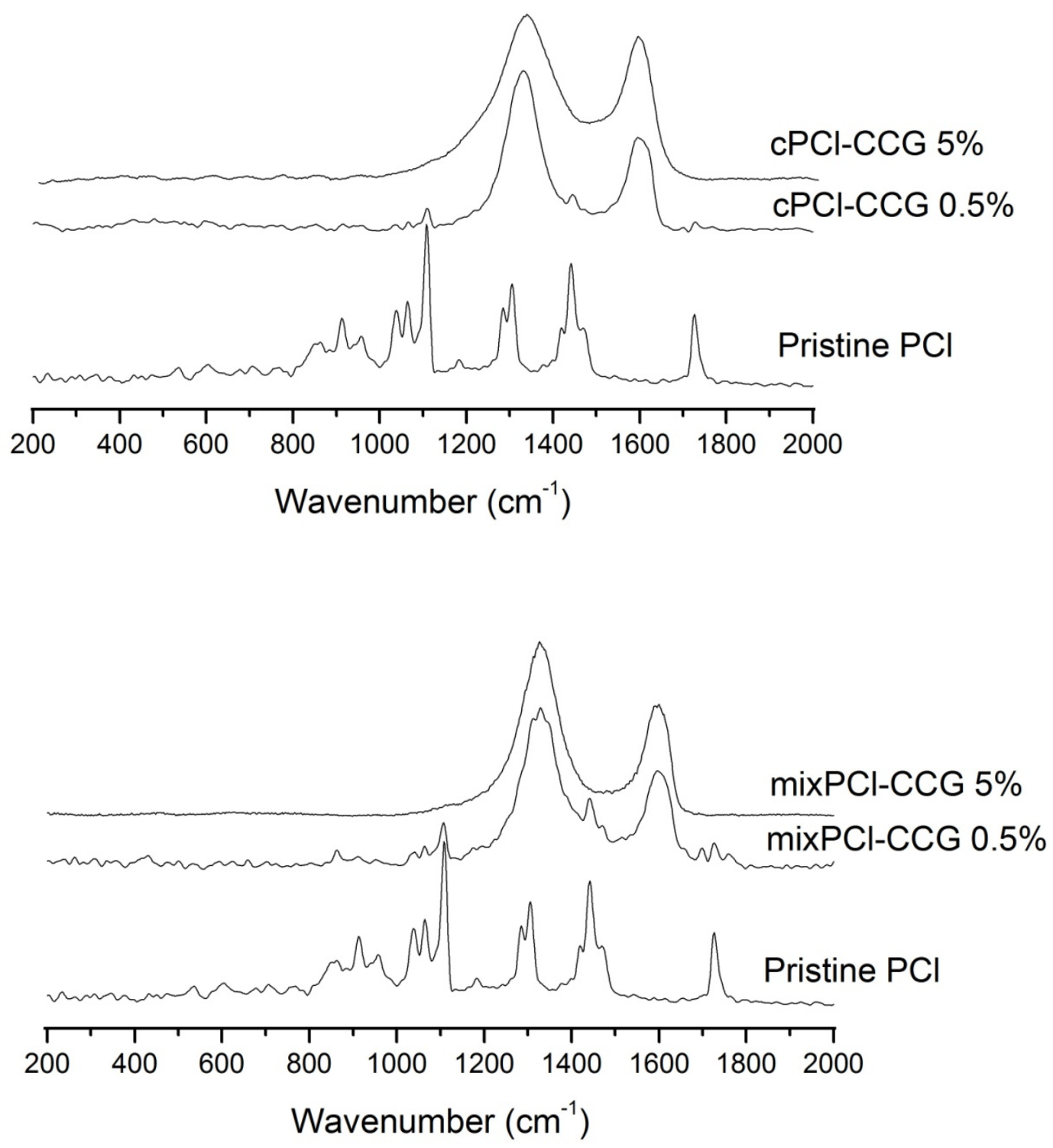

Figure 5. Raman spectra of PCl-CCG composites. The two significant peaks at 1337 and $1602 \mathrm{~cm}^{-1}$ correspond to D and $\mathrm{G}$ band of graphene sheets.

\subsection{Material Properties}

Polycaprolactone shows conductivity of less than $10^{-15} \mathrm{~S} \mathrm{~cm}^{-1}$ as a pristine polymer.[23] As expected, increasing the graphene content results in much improved conductivity (Fig. 6), 
with conductivity increasing by more than 13 orders of magnitude on addition of less than 5 \% graphene. At low graphene contents (< $1 \%$ ), mixPCl-CCG samples show better conductivity than covalently linked cPCl-CCG. This is probably due to the agglomerated nature of the graphene nanosheets in the mixed blend resulting in a shorter conducting path length conducting domains surrounded by non-conducting regions. An increase in graphene content results in an increase in the size and number of these domains resulting in a flatter increase in conductivity. On the other hand, above the percolation threshold the conductivity of the well dispersed cPCl-CCG samples increases rapidly and consistently, with the addition of less than $10 \%$ graphene resulting in a conductivity of almost $10^{-2} \mathrm{~S} \mathrm{~cm}^{-1}$.

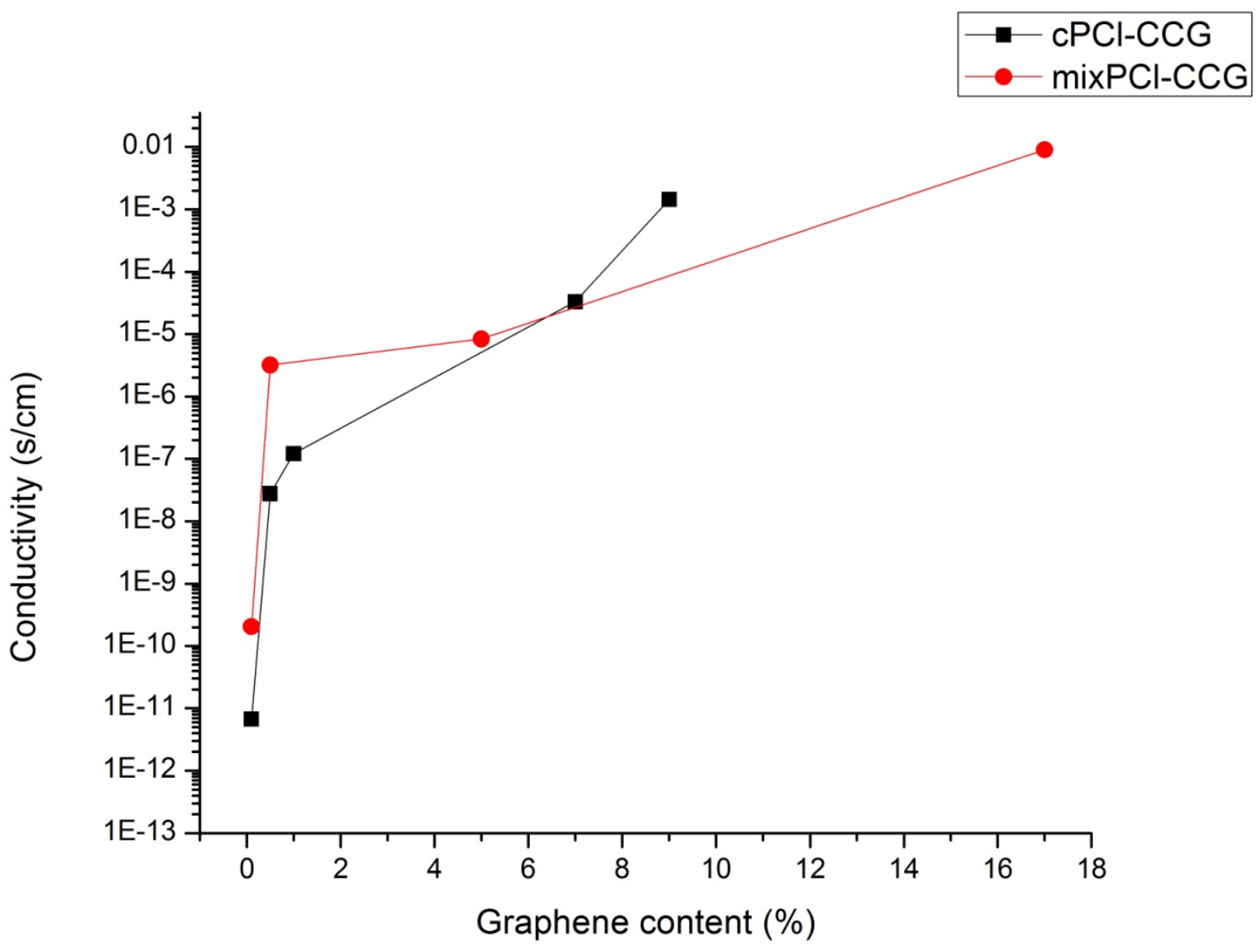

Figure 6. Conductivity measurements of PCl-CCG composites showing large increase in conductivity above the percolation threshold ( $<0.1 \%$ graphene content).

In general, the addition of graphene improves the strength of the composites but decreases the elongation at break as the interaction between graphene and the matrix restricts the 
movement of the polymer chains. Figure 7a shows the increase in tensile yield strength in both covalently linked and mixed method materials. In covalently attached composites, the addition of just $0.5 \%$ graphene increased specific strength by almost $50 \%$ and trebled it on addition of $5 \%$. Similarly the specific modulus increases from $88 \mathrm{MPa}$ in pristine PCl to 252 MPa to $591 \mathrm{MPa}$ across the same range.
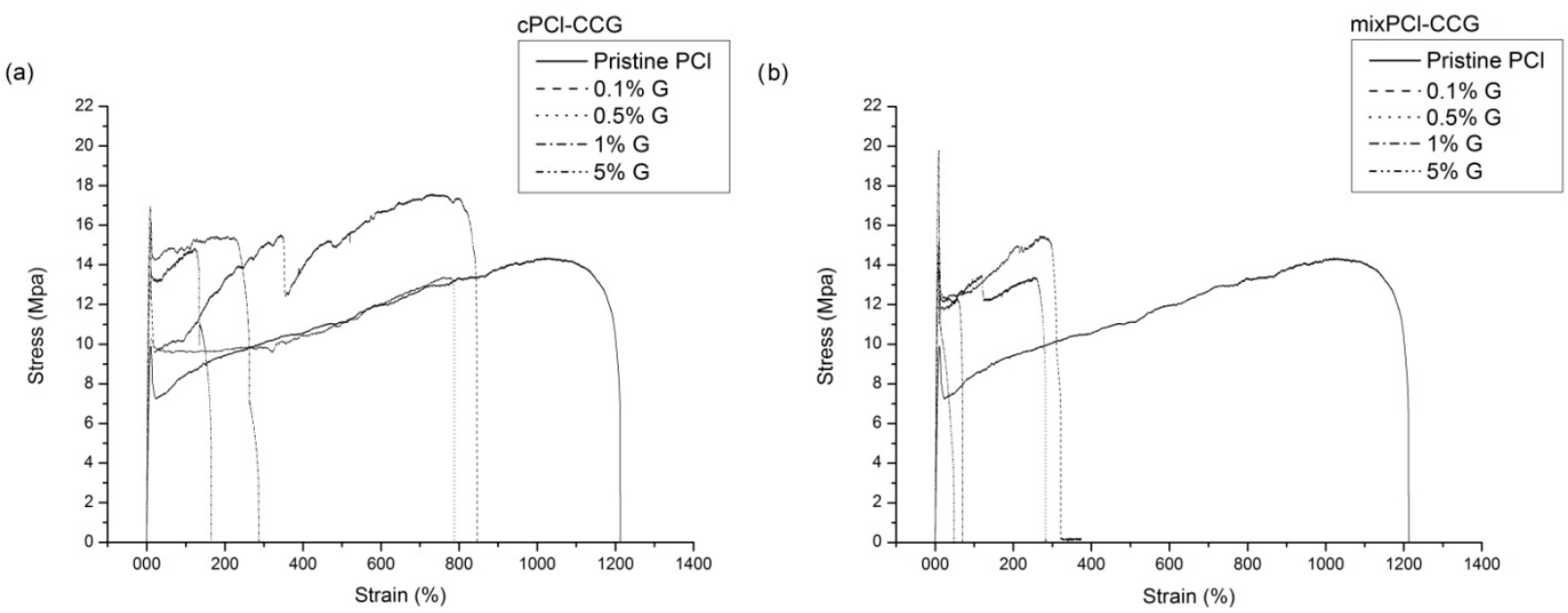

Figure 7. Stress-strain curves of (a) cPCl-CCG and (b) mixPCl-CCG composites showing the large increase in tensile strengths and reductions in elongation at break.

In the composites prepared by the mixing method (Fig. 7b), the improvement in the tensile strength on the addition of graphene is less than that shown by the covalently linked composites, while the elongation at break decreased far more significantly. For a mixture with $5 \%$ graphene, the elongation at break is decreased to just $69 \%$ while the specific tensile strength is increased to $19.9 \mathrm{MPa}$, as compared to $160 \%$ and $39.5 \mathrm{MPa}$ for a similar covalently linked material. The increased strength and plasticity of the covalently-linked material is due to the far better dispersion of graphene nanosheets throughout the sample. (Table 1) 
Table 1. Mechanical properties of polycaprolactone, covalently-linked composites cPClCCG and binary mixtures mixPCl-CCG.

\begin{tabular}{ccccc}
\hline & $\begin{array}{c}\text { Graphene } \\
\text { Content } \\
(\%)\end{array}$ & $\begin{array}{c}\text { Specific } \\
\text { Strength } \\
(\mathrm{KN} . \mathrm{m} / \mathrm{kg})\end{array}$ & $\begin{array}{c}\text { Specific } \\
\text { Modulus } \\
(\mathrm{KN} . \mathrm{m} / \mathrm{kg})\end{array}$ & $\begin{array}{c}\text { Elongation at } \\
\text { Break }(\%)\end{array}$ \\
\hline Polycaprolactone & 0 & $13.5( \pm 3)$ & $88.7( \pm 17)$ & $1212( \pm 86)$ \\
\hline \multirow{3}{*}{ Covalent } & 0.1 & $12.3( \pm 2)$ & $83.0( \pm 12)$ & $842( \pm 57)$ \\
& 0.5 & $21.9( \pm 4)$ & $252.7( \pm 34)$ & $788( \pm 38)$ \\
& 1 & $24.3( \pm 4)$ & $356.6( \pm 50)$ & $286( \pm 18)$ \\
Mixture & 5 & $39.5( \pm 7)$ & $591.1( \pm 103)$ & $166( \pm 12)$ \\
& 0.1 & $12.6( \pm 3)$ & $130.1( \pm 9)$ & $321( \pm 53)$ \\
& 0.5 & $17.5( \pm 1)$ & $256.0( \pm 48)$ & $282( \pm 28)$ \\
& 5 & $19.9( \pm 3)$ & $366.1( \pm 57.6)$ & $69.5( \pm 11)$ \\
& 17 & $63.4( \pm 14)$ & $1147.1( \pm 232)$ & $48.4( \pm 12)$ \\
\hline
\end{tabular}

\subsection{Biocompatibility}

Polycaprolactone is a well-established biocompatible and biodegradable material having found use in many applications including drug delivery, sutures and as a scaffold for tissue engineering. Fibroblast cells adhered to and proliferated on films cast from PCl, cPCl-CCG $0.5 \%$ and cPCl-CCG $5 \%$, indicating that the material surface were suitable for attachment of cells, and did not leach any toxic compounds through the culture period. After 48 hours in culture media, cells were imaged (Fig. 8) and the images analysed for cell density on the surfaces and proportion of dead cells (cells that were permeable to propidium iodide). On $\mathrm{PCl}$, an average of $400 \pm 100$ cells $\mathrm{mm}^{-2}$ were observed on the surface, with $1.8 \pm 0.8 \%$ dead cells. On cPCl-CCG $0.5 \%$ L-929 cells were at $380 \pm 70$ cells $/ \mathrm{mm}^{2}$ with $1.1 \pm 0.1 \%$ dead cells, and on cPCl-CCG $5 \%$ the cell density was $450 \pm 90$ cells $/ \mathrm{mm}^{2}$ with $2 \pm 1 \%$ dead cells. The cell density across the surfaces of all materials was inconsistent leading to a somewhat variable cell density across difference microscope fields, so the slight increase in average cell 
density on cPCl-CCG 5 \% was not statistically significant. No differences were observed in the growth of L-929 cells on mixPCl-CCG compared to cPCl-CCG materials. Cell density increased approximately 8 times from the seeding density on all materials (including tissue culture plastic - data not shown), indicating that the proliferation of cells was not significantly modified by the PCl or PCl-CCG materials.

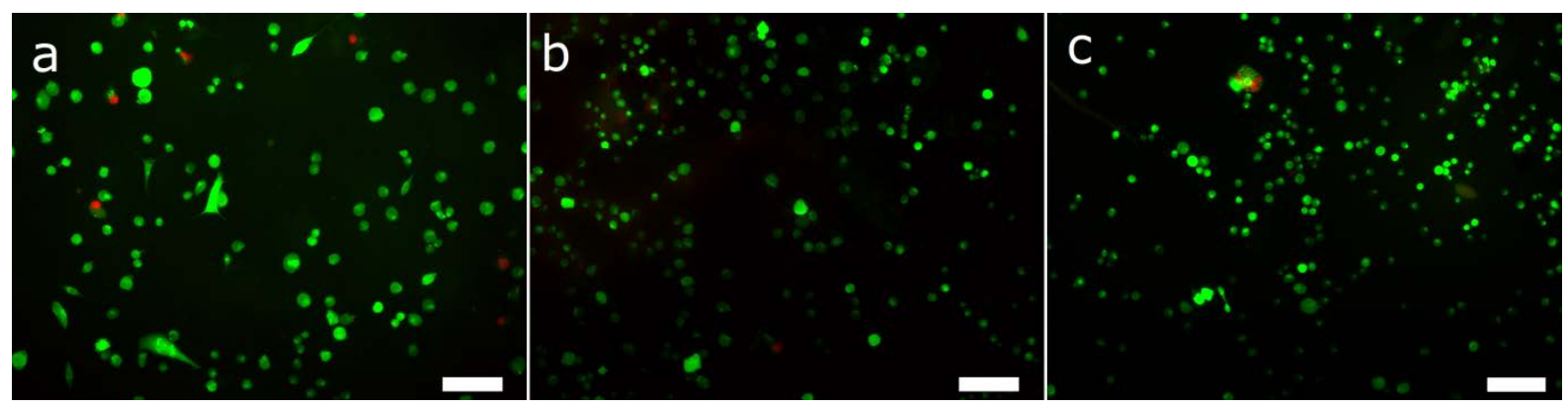

Figure 8. Live L-929 cells stained with calcein (green) and prodidium iodide (red) on sheets of a) PCl, b) cPCl-CCG 0.5\% and c) cPCl-CCG 5\%. The scale bars indicate $100 \mu \mathrm{m}$.

The growth of three different cell types was assessed on the cPCl-CCG materials and compared to growth on pristine PCl and tissue culture plastic. Fibroblast (L-929), neural (PC12) and muscle (C2C12) cell lines were seeded onto the materials, and the cell number was assessed at various time points over 4 days by Pico Green Assay. The fluorescence generated by the Pico Green reagent is proportional to cell number in each well of a 96-well plate. The results are shown in Figure 9, indicating that all cell lines proliferated on PCl, cPCl-CCG $0.5 \%$ and $5 \%$ in a similar way to tissue culture plastic, although the cell number was consistently slightly greater on tissue culture plastic up to 48 hours across all cell lines. Both L-929 and C2C12 showed typical growth curves on the materials, with a small increase in the cell number between seeding and 48 hours, then a log phase of cell proliferation between 48 72 hours. The decrease in cell density at 96 hours is attributed to cells becoming overgrown after 3 days, and depleting the nutrients in the media. Overall, a 7-8 fold increase in fluorescence was seen between seeding and the maximum cell density at 72 hours. PC-12 
cells grown on $\mathrm{PCl}$ or $\mathrm{CPCl}-\mathrm{CCG} 0.5 \%$ were slighly less adhered at $24 \mathrm{~h}$ than the original seeding density. However, after 48 hours the adhesion of the cells was similar to tissue culture plastic. Interestingly, cPCL-CCG 5\% showed the same adhesion of cells at 24 hours as tissue culture plastic. Over the 4 days of culture a 2-3 fold increase in fluorescence was observed from PC-12 cells grown on all PCl-containing materials, identical to that on tissue culture plastic. PC-12 cells often adhere poorly to surfaces without collagen coating (which was not performed here), and so these results are a good indication that the materials are suitable to support the adhesion and proliferation of even cells lines that typically exhibit poor materials compatibility.
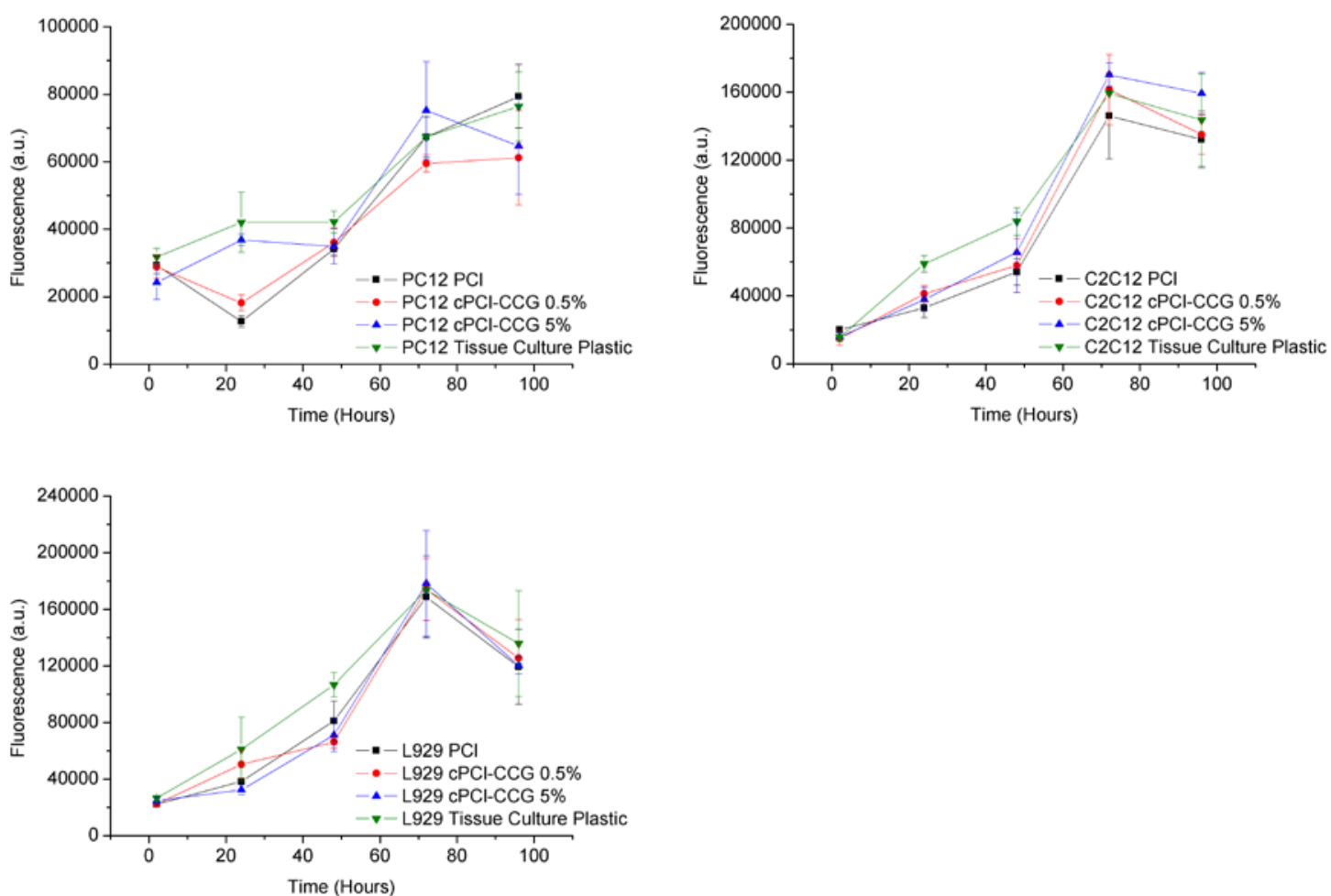

Figure 9. Growth curves of three cell lines on PCl, tissue culture plastic and cPCl-CCG materials. Fibroblasts (a, L-929 cell line), muscle cells (b, C2C12 cell line) and neural cells (c, PC12 cell line) all adhered to and proliferated on the materials for 72-96 hours. Each point represents the average of three measurements, and the error bars indicate one standard deviation. 


\section{Conclusions}

In this paper we have presented two methods for the synthesis of polycaprolactone graphene composites. Previous work on graphene oxide [20, 21] had introduced a mixing method for the production of graphene oxide polymer materials. Adapting this method using highly reduced, well dispersed graphene resulted in graphene/polycaprolactone composites with good mechanical and conducting properties but poor graphene dispersion in the matrix. Covalently linking the polymer to the graphene chains resulted in improved mechanical properties, conductivity and very homogeneously dispersed graphene nanosheets. The excellent processability and solubility of these covalently linked materials makes them good candidates for use in a number of applications including conducting biodegradable systems for tissue engineering.

\section{Acknowledgements}

This work has been supported by the Australian Research Council under the Superscience fellowship. We also acknowledge the Australian National Fabrication Facility (ANFF) for providing both materials and instrumentation. We thank Prof. Geoff Spinks for helpful scientific discussion. 


\section{References}

[1] Hussain F, Hojjati M, Okamoto M, Gorga RE. Review article: Polymer-matrix nanocomposites, processing, manufacturing, and application: An overview. JCoMa. 2006;40(17):1511-75.

[2] Thuau D, Koutsos V, Cheung R. Electrical and mechanical properties of carbon nanotube-polyimide composites. J Vac Sci Technol B. 2009;27(6):3139-44.

[3] Zuev VV, Kostromin SV, Shlykov AV. The effect of fullerene fillers on the mechanical properties of polymer nanocomposites. Mech Compos Mater. 2010;46(2):147-54.

[4] Park SY, Park J, Sim SH, Sung MG, Kim KS, Hong BH, et al. Enhanced Differentiation of Human Neural Stem Cells into Neurons on Graphene. Adv Mater. 2011;23(36).

[5] Geim AK, MacDonald AH. Graphene: Exploring carbon flatland. PhT. 2007;60(8):3541.

[6] Si Y, Samulski ET. Synthesis of water soluble graphene. Nano Lett. 2008;8(6):167982.

[7] Stankovich S, Dikin DA, Dommett GHB, Kohlhaas KM, Zimney EJ, Stach EA, et al. Graphene-based composite materials. Nature. 2006;442(7100):282-6. 
[8] Quan H, Zhang BQ, Zhao Q, Yuen RKK, Li RKY. Facile preparation and thermal degradation studies of graphite nanoplatelets (GNPs) filled thermoplastic polyurethane (TPU) nanocomposites. Compos Part a-Appl S. 2009;40(9):1506-13.

[9] Eda G, Chhowalla M. Graphene-based Composite Thin Films for Electronics. Nano Lett. 2009;9(2):814-8.

[10] Kim H, Macosko CW. Processing-property relationships of polycarbonate/graphene composites. Poly. 2009;50(15):3797-809.

[11] Das B, Prasad KE, Ramamurty U, Rao CNR. Nano-indentation studies on polymer matrix composites reinforced by few-layer graphene. Nanot. 2009;20(12).

[12] Fan HL, Wang LL, Zhao KK, Li N, Shi ZJ, Ge ZG, et al. Fabrication, Mechanical Properties, and Biocompatibility of Graphene-Reinforced Chitosan Composites. Biomacromolecules. 2010;11(9):2345-51.

[13] Fernandes SCM, Freire CSR, Silvestre AJD, Neto CP, Gandini A, Berglund LA, et al. Transparent chitosan films reinforced with a high content of nanofibrillated cellulose. Carbohydr Polym. 2010;81(2):394-401.

[14] Kim IH, Jeong YG. Polylactide/Exfoliated Graphite Nanocomposites with Enhanced Thermal Stability, Mechanical Modulus, and Electrical Conductivity. J Polym Sci Pol Phys. 2010;48(8):850-8.

[15] Yang XM, Li LA, Shang SM, Tao XM. Synthesis and characterization of layer-aligned poly(vinyl alcohol)/graphene nanocomposites. Poly. 2010;51(15):3431-5. 
[16] Yeh JT, Yang MC, Wu CJ, Wu CS. Preparation and Characterization of Biodegradable Polycaprolactone/Multiwalled Carbon Nanotubes Nanocomposites. J Appl Polym Sci. 2009;112(2):660-8.

[17] Janigova I, Lednicky F, Moskova DJ, Chodak I. Nanocomposites with Biodegradable Polycaprolactone Matrix. Macromol Symp. 2011;301:1-8.

[18] Diba M, Fathi MH, Kharaziha M. Novel forsterite/polycaprolactone nanocomposite scaffold for tissue engineering applications. MatL. 2011;65(12):1931-4.

[19] Saeed K, Park SY, Lee HJ, Baek JB, Huh WS. Preparation of electrospun nanofibers of carbon nanotube/polycaprolactone nanocomposite. Poly. 2006;47(23):8019-25.

[20] Hua L, Kai W, Inoue Y. Synthesis and characterization of poly(epsilon-caprolactone)graphite oxide composites. J Appl Polym Sci. 2007;106(3):1880-4.

[21] Kai WH, Hirota Y, Hua L, Inoue Y. Thermal and mechanical properties of a poly(epsilon-caprolactone)/graphite oxide composite. J Appl Polym Sci. 2008;107(3):1395-400.

[22] Hummers WS, Offeman RE. Preparation of Graphitic Oxide. J Am Chem Soc. 1958;80(6):1339-.

[23] Kovtyukhova NI, Ollivier PJ, Martin BR, Mallouk TE, Chizhik SA, Buzaneva EV, et al. Layer-by-layer assembly of ultrathin composite films from micron-sized graphite oxide sheets and polycations. Chem Mater. 1999;11(3):771-8.

[24] Xu Z, Gao C. In situ Polymerization Approach to Graphene-Reinforced Nylon-6 Composites. Macromolecules. 2010;43(16):6716-23. 
[25] Gudarzi MM, Sharif F. Molecular level dispersion of graphene in polymer matrices using colloidal polymer and graphene. JCIS. 2012;366(1):44-50.

[26] Chin SJ, Hornsby P, Vengust D, Mihailovic D, Mitra J, Dawson P, et al. Composites of poly(e-caprolactone) and Mo6S3I6 Nanowires. Polym Adv Technol. 2012;23(2):14960.

[27] Kister G, Cassanas G, Bergounhon M, Hoarau D, Vert M. Structural characterization and hydrolytic degradation of solid copolymers of d,l-lactide-co- $\varepsilon$-caprolactone by Raman spectroscopy. Poly. 2000;41(3):925-32.

[28] Di Foggia M, Corda U, Plescia E, Taddei P, Torreggiani A. Effects of sterilisation by high-energy radiation on biomedical poly-(epsilon-caprolactone)/hydroxyapatite composites. J Mater Sci Mater Med. 2010;21(6):1789-97.

[29] Li D, Muller MB, Gilje S, Kaner RB, Wallace GG. Processable aqueous dispersions of graphene nanosheets. Nat Nanotechnol. 2008;3(2):101-5.

[30] Hasin P, Alpuche-Aviles MA, Wu Y. Electrocatalytic Activity of Graphene Multilayers toward I-/I3-: Effect of Preparation Conditions and Polyelectrolyte Modification. The Journal of Physical Chemistry C. 2010;114(37):15857-61.

[31] Pimenta MA, Dresselhaus G, Dresselhaus MS, Cancado LG, Jorio A, Saito R. Studying disorder in graphite-based systems by Raman spectroscopy. Phys Chem Chem Phys. 2007;9(11):1276-91. 
